\author{
Journal of Research \& Health \\ Social Development \& Health Promotion \\ Research Center \\ Vol. 6, No. 5, Nov \& Dec 2016 \\ Pages: 471- 478 \\ DOI: 10.18869/acadpub.jrh.6.5.471 \\ Original Article
}

1. Correspondence to: Department of Psychiatric Nursing, School of Nursing and Midwifery, Infectious Diseases Research Center, Kashan University of Medical Sciences, Kashan, Iran

Email: aghajani1362@yahoo.com

2. Department of Nursing, School of Nursing and Midwifery, Trauma Nursing Research Center, Kashan University of Medical Sciences, Kashan, Iran

3. Department of Nursing, School of Nursing and Midwifery, Kashan University of Medical Sciences, Kashan, Iran

Received: 6 Aug 2013

Accepted: 22 Apr 2014

How to cite this article: Aghajani M, Safa A, Helli E, Alizade M. High-Risk behaviors and their relationship with demographic characteristic in girl and boy adolescents. $J$ Research \& Health2016; 6(5): 471- 478.

\section{High-Risk behaviors and their relationship with demographic characteristic in girl and boy adolescents \\ Mohammad Aghajani ${ }^{1}$, Azade $\mathrm{Safa}^{2}$, Elham Helli ${ }^{3}$, Mahbobeh Alizade ${ }^{3}$}

\begin{abstract}
Prevalence of high-risk behaviors has become one of the most important concerns in nowadays society. Aim of this study is was investigation of assay high-risk behaviors and their relations with demographic characteristics in adolescents. This study was performed on 400 of high school adolescents that were selected by randomized classify method. Data were collected by using of questionnaire including individual-social characteristics questionnaire and high-risk behaviors scale in assault and battery, tobacco, high-risk physical and sexual relations, lack of exercise and law breaking domains and then were analyzed. Prevalence of high-risk behaviors was $28.7 \%$ in boys and $22.5 \%$ in girls. Significant difference was founded between general high-risk behaviors and tobacco; sexual high-risk behaviors and Acquired Immunodeficiency Syndrome (AIDS) behaviors, AIDS and law breaking domains in girls and boys also significant relationship was found between high-risk behaviors and some individual, family and social factors. Findings of this study could empowerment health systems in accurate planning for screening and counseling of high-risk behaviors.
\end{abstract}

Keywords: Adolescent, Behavior, Demographic, High-Risk

\section{Introduction}

Adolescence is the most important period of life among the different periods of human life. This intermediate stage is transition from childhood to adulthood and the beginning of changes in the physical, psychological and social which affects person's performance in adulthood [1]. Adolescence is critical period in the life in which some of the main behavioral models of the man are formed [2]. According to the census of 2005 in Iran, $21.9 \%$ of the population was people of 10-19 years who were about 15 million people [3]. Hence, health behaviors in adolescences are important because several of death and disease in adolescence has been associated with high-risk behaviors [4]. Adolescence is also important phase of transition from period under parental control to the independence [5]. As, important of adolescent in heath and development society, it is important investigated of risk behaviors in adolescence and youth in particular in for high school students [6]. The high-risk behaviors are defined as behaviors which threat Health and well-being of adolescences, youth and other society's members [7]. Engage in risky behaviors such as smoking, alcohol and drug abuse, violence, risky sexual behavior and 
suicide suicidal behaviors lead to complications and mortality in both young and adult's people. Distribution and prevalence of risky behaviors varied in different races and ethnicities, gender, age and regions [8]. Today, The prevalence of risk behaviors to become one of the most important concerns of the international society and despite the efforts made during the recent years the rate of risky behaviors have risen dramatically among Iranian adolescences [9]. Sweeting and et al. compared risk behaviors of two groups of West of Scotland adolescences in 1990 and 2003. They reported that significantly increased average of drinking, drug use, and early sexual activity and experience multiple sexual partners. On the other hand, significant increasing in drug use and risky sexual behaviors among female adolescence has long-term consequences for the health of young females and society. Many highrisk behaviors such as tobacco, alcohol and drug use and risky sexual behavior begin in puberty and continue into adulthood [10]. According to Eaton et al. $18.5 \%$ of high school students in the United States carried guns during the month prior to the study and $35.9 \%$ were involved in altercation during the last year (6). A study in Malaysia reported that $27.9 \%$ of high school students involved in a physical altercation and $6.6 \%$ once or more were wounded in physical altercation. Also $5.9 \%$ of students had weapon and $7.3 \%$ had felt unsafe [11]. Epidemiological studies have also shown that many adolescent abused drugs in schools [12]. A study in the Sistan and Baluchistan province has also reported that about $22.1 \%$ of high school students had weapon (such as; gun or knife) at least for day in their life and $53.3 \%$ at least one were involved in an altercation during the last year and $41.8 \%$ also were wounded in the altercation [11]. Review of various opinions and theories showed that there is not deterministic approach in high-risk behaviors [13]. However, various theories have been implicated variety of factors in risky behaviors. Some have referred not to use their leisure and others have highlighted the role of social factors in this context [7]. In Iran, factors of trends and lifestyles and intervention programs in students have been less attention [14]. Therefore, aim of this study was to determine risky behaviors and its relationship with socio-demographic factors in boys and girls Iranian adolescent. It is hoped that by accepting the principle of prevention as an effective way to avoid risky behaviors, we could to detect roots of tendency adolescents toward risk behaviors and able to eliminate the adolescents' vulnerability factors to these high-risk behaviors

\section{Method}

This study used a cross-correlation method and was conducted from March to May 2012. The study population consisted of all male and female students studying at grades three of Kashan's high schools in 2012, Iran. Sample size was calculated based on previous study. Then, 384 participants was estimated to be needed based on following parameters $(\beta=0.20$, $\alpha=0.05, \mathrm{~d}=0.05$ ). However, 400 participants were selected to compensate the possible attrition. Sampling was conducted in several stages. Firstly, the city of Kashan was divided into five regions (including the central, north, south, and west and east areas). Subsequently, two high schools (one female and one male high school) were randomly selected in each area and 40 students ( 20 female, 20 male) were randomly selected from the list of the students in grade three in each high school.

Inclusion criteria were: age of 15-21 years old, studying in grad three, lack of physical and mental disabilities, not having a known physical or mental illness, having an Iranian nationality and living in Kashan city. Having a known physical or mental illness, age $>21$ year and incomplete response to questionnaire were selected as exclusion criteria. All ethical considerations of the study were approved by the institutional review board and the research ethics committee in the university. All participants in the study were informed of the study's aim and signed written consent form and were assured of the confidentiality of their personal information and nature of voluntary participation. Also permissions were sought from the high schools authorities. Then the research instrument was given to the students. 
The research instrument was consisted of two parts which include socio-demographic questionnaire (20 items) and The Risky Behavior Scale (YRBSS).

YRBSS has 18 items that was adjusted and designed from the risk behavior questionnaire by the America's Centers for Disease Control (CDC) in 1989. Items of YRBSS assess a set of behaviors that threat the physical health and increase the possibility of illness, social problems and death in adolescents and adults. In the present study, questionnaire was used to assess risk behaviors in the Fields assaults, tobacco, drugs, risky sexual behaviors, physical and sedentary lifestyle, lawlessness which examines the frequency and severity of this behavior in the form of monthly and annual 18 items. The test-retest reliability of the YRBSS was assessed by Brenner et al and the Kapa's coefficient of the items ranged from 23.6 to 90.5 for individual items [12].

Mehrabi et al. have validated the Persian version of the YRBSS by content validity method and the alpha coefficient of the scale was 0.79 for the total scale [7]. All items of the scale are responded in a five-choice Likert scalewith options ranging from ' $0=$ never' to' $4=$ very much'. Summing the responses yields a score ranging from 0 to 72 , with higher scores showing a more risky behavior. The cut-off point for risky and none risky behavior is the score of 17.44 [7].

Data analysis was performed by using SPSS20. Descriptive statistics (mean, frequency, percentage) and T-test, chi-square test, ANOVA, Spearman correlation coefficient and Regression were used to examine the relationship between the variables. P-value less than 0.05 was considered as significant level in all the tests.

\section{Results}

Among all of participants, 190 participant were females (47.6\%) with mean age of $16.92 \pm 0.78$ years old and 210 were males $(52.4 \%)$ with a mean age of $17.83 \pm 0.96$ years old. In total, $161(40.1 \%)$ of the students were the first child of the family and 174 ones (43.4\%) stated that their family has two children. Parents of 375 students $(94.5 \%)$ were alive. (Table 1)

\begin{tabular}{|c|c|c|c|c|c|c|}
\hline \multirow{2}{*}{ Demographic characteristics } & \multicolumn{3}{|c|}{ Yes } & \multicolumn{3}{|c|}{ No } \\
\hline & $\mathrm{N}$ & \multicolumn{2}{|l|}{$\%$} & $\mathrm{~N}$ & \multicolumn{2}{|r|}{$\%$} \\
\hline $\begin{array}{l}\text { Death of a family member in the last } \\
6 \text { months }\end{array}$ & 21 & \multicolumn{2}{|l|}{5.2} & 380 & \multicolumn{2}{|c|}{94.8} \\
\hline Experiencing parental divorce & 11 & \multicolumn{2}{|l|}{2.7} & 390 & \multicolumn{2}{|c|}{97.3} \\
\hline Run away from the home & 7 & \multicolumn{2}{|l|}{1.7} & 394 & \multicolumn{2}{|c|}{98.3} \\
\hline Satellites at home & 88 & \multicolumn{2}{|l|}{22} & 312 & \multicolumn{2}{|r|}{78} \\
\hline Interest to see the satellite & 200 & 50 & & 200 & \multicolumn{2}{|r|}{50} \\
\hline \multirow{2}{*}{ Family factors } & \multicolumn{2}{|c|}{ Low } & \multicolumn{2}{|c|}{ Moderate } & \multicolumn{2}{|c|}{ High } \\
\hline & $\mathrm{N}$ & $\%$ & $\mathrm{~N}$ & $\%$ & $\mathrm{~N}$ & $\%$ \\
\hline Dependence of the family & 27 & 6.7 & 93 & 33.3 & 280 & 70 \\
\hline Compliance with parents & 27 & 6.7 & 114 & 28.5 & 259 & 64.8 \\
\hline The interest in the family gathering & 23 & 5.8 & 70 & 17.5 & 307 & 76.7 \\
\hline The malaise in the family & 174 & 43.5 & 146 & 36.5 & 80 & 20 \\
\hline Thinking of running away from home & 364 & 91 & 18 & 4.5 & 18 & 4.5 \\
\hline $\begin{array}{l}\text { Problem solving with aggression in } \\
\text { the family }\end{array}$ & 278 & 69.5 & 79 & 19.8 & 43 & 10.7 \\
\hline $\begin{array}{l}\text { Having intimate relationships with } \\
\text { parents }\end{array}$ & 12 & 3 & 75 & 18.8 & 313 & 78.2 \\
\hline Conflict and dispute between parents & 183 & 45.8 & 178 & 44.5 & 39 & 9.7 \\
\hline
\end{tabular}

Prevalence of risky behaviors in females and males was $28.7 \%$ and $22.5 \%$.

T-test showed significant difference between girls and boys students' overall risky behavior score $(\mathrm{p}<0.021)$, so thatboysrisky behavior $(15.35 \pm 6.67)$ was more than girls $(13.89 \pm 5.96)$. Also the scores of dimensions of smoking, risky sexual behaviors and Acquired Immunodeficiency Syndrome (AIDS) and offence in boy students was more than girls $(\mathrm{p}<0.05)$ (Table 2$)$. 
High-risk behaviors in teenagers

Table 2 Comparison of dimensions of high risk behaviors among the adolescents

\begin{tabular}{|c|c|c|c|c|c|c|}
\hline \multirow{2}{*}{$\begin{array}{l}\text { Dimensions of high } \\
\text { risk behaviors }\end{array}$} & \multicolumn{2}{|c|}{ Girl } & \multicolumn{2}{|c|}{ Boy } & \multicolumn{2}{|c|}{$\mathrm{p}$-value } \\
\hline & Mean & SD & Mean & SD & $\mathrm{t}$ & $\mathrm{p}$ \\
\hline Battery & 0.83 & 1.71 & 0.84 & 1.68 & 0.03 & 0.9 \\
\hline Tobacco & 0.43 & 1.26 & 0.85 & 1.72 & 2.74 & 0.006 \\
\hline Drugs & 0.34 & 1.09 & 0.29 & 0.85 & 0.46 & 0.6 \\
\hline $\begin{array}{l}\text { Risky sexual behaviors } \\
\text { and Aids }\end{array}$ & 4.77 & 2.64 & 5.33 & 2.67 & 2.09 & 0.03 \\
\hline $\begin{array}{l}\text { Physical and sedentary } \\
\text { lifestyle }\end{array}$ & 4.6 & 2.4 & 6.68 & 2.1 & 0.35 & 0.7 \\
\hline Lawlessness & 0.9 & 1.6 & 1.35 & 2.03 & 2.49 & 0.014 \\
\hline $\begin{array}{l}\text { The whole score of risk } \\
\text { behaviors }\end{array}$ & 13.89 & 5.96 & 15.35 & 6.67 & 2.31 & 0.021 \\
\hline $\begin{array}{l}\text { The frequency of risk } \\
\text { behaviors }\end{array}$ & & $\mathrm{N}$ & & & $\%$ & \\
\hline No & 148 & & 77.5 & 150 & & 71.3 \\
\hline Yes & 43 & & 22.5 & 60 & & 28.7 \\
\hline
\end{tabular}

Table 3 Distribution of some risky behaviors items in the adolescents

\begin{tabular}{lcccc}
\hline Items of risky behavior & Never & Low & Sometimes & High \\
\hline Carry of cold arms & $91.5 \%$ & $5.2 \%$ & $1.8 \%$ & $1.5 \%$ \\
Having a physical fight in the past & $66.5 \%$ & $22.5 \%$ & $6.9 \%$ & $4.1 \%$ \\
month & $96.1 \%$ & $1.8 \%$ & $1 \%$ & $1.1 \%$ \\
Smoking & $78.1 \%$ & $10.3 \%$ & $5.3 \%$ & $6.3 \%$ \\
Hookah & $94 \%$ & $3.1 \%$ & $0.8 \%$ & $2.1 \%$ \\
The use of drugs to stay awake & $89 \%$ & $7.7 \%$ & $2 \%$ & $1.3 \%$ \\
Use of medication to reduce anxiety & $46.7 \%$ & $30.3 \%$ & $12.5 \%$ & $10.5 \%$ \\
Talk with your parents about sex & $6.8 \%$ & $17.1 \%$ & $19 \%$ & $57.1 \%$ \\
$\begin{array}{l}\text { The Guidelines on HIV } \\
\text { transmission }\end{array}$ & $67.2 \%$ & $25 \%$ & $4 \%$ & $3.8 \%$ \\
Deliberately don't going to school & & & & \\
\hline
\end{tabular}

As presented in Table 3, 91.5\% of participants did not carry any weapons (gun, knife). Also $18 \%$ adolescents thought are more obese and $17.5 \%$ thinner of their peers.

The relationship between risk behavior and socio-demographic data, statistical tests showed positive significant correlation between risky behaviors with age, malaise and fatigue at home, problem solving in family with aggression, dispute and conflict between parents and dispute and conflict with parents. Also negative significant correlation was found between risky behaviors with dependence of the family, compliance with parents and interested in attending the home and family

Significant difference was found between the score of risky behaviors and death of family's member in the last 6 months history of running away from home, thoughts about of running away from home, have an intimate relationship with parents, having intimate relationship with family's members, satellite at home and interested to watch satellite programs.

\section{Discussion}

The results of this study showed that $28.7 \%$ of boys and $22.5 \%$ of girls had risky behaviors. Mehrabi et al. have studied the prevalence of risky behaviors among Isfahan university students and reported that $25.7 \%$ of girls and $38 \%$ boys had risky behaviors so showed that the risky behaviors of university students are more than high school students [15]. According to the importance of the life cycle and its consequences, level of risky behaviors in the study's population is warning and it is requires give planning and attract attention of health authorities. The present study showed that risky behaviors were more prevalent among males than female students and this finding was in consistent with findings of Barikani et al. in Tehran [2], Sychareun et al. 
in Laos [22] and Zink in china [26]. This finding may be attributed to the fact that boys usually have broader social relations and have more freedom, are more unrestrained and experience less parental supervisions than girls. Then they are more predisposed to attempt risky behaviors than girls. In this study, boys had higher score than girls' students in domain of tobacco. In study's Grunbaum et al. in America, $66.9 \%$ of students experienced smoking which this rate was higher in boys than girls [17]. In present study, $3.9 \%$ of adolescents had used smoking but while $21.9 \%$ of them had used hookah. Lee et al. in China found that $18 \%$ of students had experienced smoking [19] also in Maziak's study in high school adolescents of Syria found $16 \%$ of boys and $7 \%$ of girls had experienced smoking [16]. Although the harmful effects of hookah is not less than smoking but because of better social status tend to use hookah is higher among adolescents. While results of researches indicate increasing in tobacco's use among boys adolescent than girls, but there is little gender difference in smoking in both sexes in aged 13-15 years in developing countries, sex ratio of smoking is changing. This showed increasing of potential danger in smoking among women [18]. Meanwhile cultural issues greatly affect the incidence of risky behavior [20]. In our culture, the alcohol, tobacco and drug use among adolescents is not common but these small amounts are disturbance. The present study also showed that boy adolescents had higher score than girls. Study's Garmarodi et al., among Tehran city's students reported sexual relationship of boys and girls was $27.8 \%$ and $12.8 \%$ respectively [4]. Also laos in a study reported Risky sexual behaviors among boys was higher than girls [22] but results of Soleimani Nia et al in Tehran showed no difference between boys and girls [27]. Adolescent's involvement in risky sexual behaviors has clear negative consequences for society. Adolescents are at high risk for negative consequences of risky sexual behaviors, such as HIV, sexually transmitted diseases and unwanted pregnancies [24]. Almost half of all sexually transmitted infections (STIs) occur annually among people under age 25 in the United States. About 1.9 million adolescents are infected with one or more sexually transmitted infections (STIs) in the United States each year [25]. In the present study of $46.7 \%$ of adolescents were not discussed sexual issues with their parents and $42.9 \%$ of them had not guidance about HIV transmission in low or not at all.

In this study, boys have score higher than girls in lawlessness domain. While study of Soleimani Nia et.al in Tehran showed no difference between boys and girls [27]. The study Bakhshani et al. in high school students in the Sistan and Baluchistan province showed that $22.1 \%$ of students have carried weapon (gun or knife) at least one day in the life and $6.7 \%$ have gun at least once over the past year [11]. In present study $8.5 \%$ of adolescents have carried cold arm and $33.5 \%$ having physical fight in the past month. It seems with more supervision and discovers the root causes can be reduced risky behavior of in this area.

The results also showed a direct correlation between the adolescents' age and increasing in risky behaviors. This finding is consistent with results of Sweeting et al. in Scotland, Sychareun et al. in Laos and Soleimani Nia et al. in Tehran $[10,12,27]$. This result of the present study showed the necessity of new strategies in educational system. About 2\% of the student participants in the study had history of running away from home. This amount was higher in boys than girls. Since possibility of other risky behaviors, especially AIDS rises sharply in teens [9]. These findings need to be further explored. Also study in Shiraz assessed effects of family factors on girl's adolescent runaway which showed that the highest rate runaway was in the age group of 15 to 18 year [23]. The findings of this study showed risk behaviors would be reduced with family dependency, interested in the family gathering, intimate relationship with their parents and other family members and compliance with parents. Also Malaise and fatigue in the home, the family's problem 
solving with aggression, conflict between parents and conflict with parents increase highrisk behavior among youth. These findings emphasize to role of family, parenting styles, and family relationship. Results of various studies have been showed important effect of family and the factors associated with high-risk behaviors. Study of Huebner and et al. 2003 on adolescents showed parental supervision, parent teen relationships and parenting styles unrelated to age or gender had a significant correlation with risky sexual behaviors [28]. Also result of Muyibi et al.'s study in Nigeria showed that parental supervision is the most important factor in reducing risk behaviors in adolescents [5]. Adolescents who live with both parents are significantly less than in risk behaviors than other young people who have risky behaviors such as smoking, aggression, drug use, communication with deviant peers, or run away from home [5]. Studies about structure of family showed that life with parents protects of adolescents engaging in risky sexual behavior $[5,25,29]$.

Also result of Zarei's study showed that neglectful and strict parenting style provides the background for increasing of high-risk behaviors. Relationships between parents and children have the greatest effect on adolescent personality problems. As maladaptive parental relationships with each other and with children would cause problems such as anxiety, ran away from home and school, anger and aggression, lying, stealing and cheating [30]. Therefore, family is major conservation unit to deal with problems in adolescents. Efficient and stable families can prevent the occurrence of high-risk behavior in adolescents. Families at risk will lead to the person toward danger. Therefore, support of families for adolescents and familybased interventions can reduce risky behaviors [9]. In this study, adolescents who had family history of death had more high-risk behaviors. Death history of family's member wreaked family structure of solid tissue and lead to incomplete role family's members [9]. Children of these families are vulnerable emotionally and psychologically and are exposed to risky behaviors. Also the teens that have satellite at home and were interested in seeing satellite programs were more risky behavior. Satellites at home and watching its programs can cause change in attitude and behavior in teens. As in study Maleki Tabar in Tehran was found that adherence to religious values in youth that watching satellite programs have been less of group that don't saw satellite program [31]. This adherence to religious values can prevent the tendency to risky behavior. Because awareness and trainings should be started from schools and families, so in order to prevent adolescent tendency toward risky behavior suggested provision variety of recreational activities, entertainment camps, sport programs and put training classes about parenting educations. These programs can help adolescents drain emotions and diversity seeking in correct ways within the laws of school and provide respect for the autonomy of adolescents. Also because adolescents are the most important stage of life where their personality would be formed in that stage [32] health-related behavior in childhood and adolescence are fixed and training just before or consolidation is necessary [4]. Attention to mental health needs of this generation are component of priorities of the country's health development plan due to the high vulnerability of this group to problems like depression, anxiety, suicide, delinquency and drug abuse [23]. Findings of this study could empower health systems in accurate planning for screening and counseling of high-risk behaviors so that we could have healthy and dynamic society [19].

The major limitation of this study is that all data was collected by using questionnaires hence adolescent mental condition could influence on method of response. Also in this study, participants were selected only among young students, therefore, it is recommended that further studies conduct with larger sample size and the non-student youth in the study used to increase the generalize ability of the results.

\section{Conclusion}

With regard to the high risk behaviors among 
studied adolescents and their related factors could empowerment health systems in accurate planning for screening and counseling of highrisk behavior to prevent of their outcomes.

\section{Acknowledgements}

The authors are deeply thankful of the cooperation of Kashan's education department and all the students and high school authorities who cooperated and participated in this study. This study was not possible without their cooperation.

\section{Contribution}

Study design: MA

Data collection and analysis: AS, EH, MAL, MA

Manuscript preparation: MA, AS

\section{Conflict of Interest}

"The authors declare that they have no competing interests."

\section{Funding}

The author (s) received no financial support for the research, authorship and/or publication of this article.

\section{Reference}

1- Klein JD, Wilson KM .Delivering quality care: adolescents' discussion of health risks with their providers. J Adolesc Health2002; 30(3): 190-5.

2- Barikani A. High risk behaviors in adolescent students in Tehran. Iranian Journal of Psychiatry and Clinical Psychology2008; 14(2): 192-8.

3- General population housing census. Management and planning organization statistical center of Iran. Tehran: Office of information publication information; 2005.

4- Garmaroudi GR, Makarem J, Alavi SS, Abbasi Z. Health related risk behaviors among high school students in Tehran, Iran. Payesh2010; 9(1): 13-9.

5- Muyibi AS, Ajayi IOO, Irabor AE, Ladipo MMA. Relationship between adolescents' family function with socio-demographic characteristics and behaviour risk factors in a primary care facility. African Journal of Primary Health Care Fam Med2010; 2(1): 177-82.

6- Eaton DK, Kann L, Kinchen S, et al. Youth risk behavior Surveillance-United States, 2009. MMWR Surveill Summ2010; 59(5): 1-142.

7- Maher F. High risk behavior in youth recreation, trends and patterns. Journal of Human Sciences2004; 6
$: 118-44$.

8- Jankowski MK, Rosenberg HJ, Sengupta A, Rosenberg SD, Wolford GL. Development of a screening tool to identify adolescents engaged in multiple problem behaviors: the adolescent risk behavior screen (ARBS). J Adolesc Health2007; 40(2): 19-26.

9- Rahmati Najar Kolaei F, Niknami Sh, Amin Shokravi F, Farmanbar R, Ahmadi F, Afari M. Family system and i ts effect's on HIV/AIDS high risk behaviors: $A$ Qualitative Study. Journal of Guilan University of Medical Sciences2011; 20(77): 69-80.

10- Sweeting H, Jackson C, Haw S. Changes in the socio-demographic patterning of late adolescent health risk behaviours during the 1990s: analysis of two West of Scotland cohort studies. BMC Public Health2011; 26(11): 829 .

11- Bakhshani NM, Lashkaripour K, Bakhshani S, Hoseinbore M. Prevalence of risk behaviors related to intentional and unintentional injuries among adolescent high school students of sistan \& balouchestan, southeast of Iran. Tabib shargh2007; 9(3): 199-208.

12- Igwe WC, Ojinnaka N, Ejiofor SO, Emechebe GO, Ibe BC. Socio-demographic correlates of psychoactive substance abuse among secondary school students in enugu, nigeria. European Journal of Social Science 2009;12(2): 1-7.

13- Rolison MR, Scherman A. College student risktaking from three perspectives. Adolescence2003; 38(152): 689-704.

14- Jabbari Beyrami H, Bakhshian F, Vahidi R, Mohammadpour Asl A. High risk behaviors and attitudes of secondary school students in Tabriz toward drugs of abuse. Iranian Journal of Psychiatry and Clinical Psycho2008; 14(3): 350-4

15- Mehrabi HA, Kjbaf MB, Mojahed A. Expectance of high risk behaviors based on sensation seeking and demographic factors in students of Isfahan University. Quarterly Journal of Psychology Studies2010; 6(2); 141-65.

16- Maziak W. Smoking in syria: profile of a developing arab country. Int J Tuberc Lung Dis2002; 6(3): 183-91.

17- Grunbaum JA, Kann L, Kinchen SA, et al. Youth risk behavior surveillance-United States, 2001. J Sch Health2002; 72(8): 313-28.

18- Global youth tobacco survey collaborating group. Differences in worldwide tobacco use by gender: findings from the global youth tobacco survey. $J$ Sch Health2003; 73(6): 207-15.

19- Lee A, Tsang CK. Youth risk behaviour in a Chinese population: a territory-wide youth risk behavioral surveillance in Hong Kong. Public Health2004; 118(2): 88-95.

20- Kinsler J, Sneed CD, Morisky DE, Ang A. 
Evaluation of a school-based intervention for HIV/AIDS prevention among Belizean adolescents. Health Educ Res2004; 19(6): 730-8.

21- Kelishadi R, Mokhtari MR, Tavasoli AA, et al. Determinants of tobacco use among youths in Isfahan, Iran. Int J Public Health2007; 52(3): 173-9.

22- Sychareun V, Thomsen S, Faxelid E. Concurrent multiple health risk behaviors among adolescents in Luangnamtha province, Lao PDR. BMC Public Health2011; 11: 36.

23- Sepehrmanesh Z, Ahmadvand A, Yavari P, Saei R. Assessing the mental health of adolescents in Kashan, 2004. Irje2008; 4(2): 43-9.

24- Joshua D, Miller M, Donald L, et al. Pers Indiv Differ2004; 36: 1611-26.

25- Robinson S. Sexual risk taking in adolescence: examining negative gender beliefs. Studies by Undergraduate Researchers at Guelph2010; 1(4): 7-13.

26- Xing Y, Ji CY. Co-occurrence of health-risk behaviors among Beijing middle school students, China. J Adolesc Health2003;33(4):215-6.

27- Soleimani nia L, Jazaieri AR, Mohammad Khani P. Role of mental health in teenagers high risk behaviors. Welfar Social2004; 5(19): 75-90.

28- Huebner AJ, Howell LW. Examining the relationship between adolescent sexual risk- taking and perceptions of monitoring, communication, and parenting styles. $J$ Adolesc Health2003; 33(2): 71-8.

29- Newman K, Harrison L, Dashiff C, Davies S. Relationships between parenting styles and risk behaviors in adolescent health: an integrative literature review. Rev Lat Am Enfermagem2008; 16(1): 142-50.

30- Zarei E. Relationship between parent child-rearing practices and high risk behavior on basis of cloninger's scale. Journal of Shahid Sadoughi University of Medical Sciences2010; 18(3): 220-4.

31- Larijani A,Maleki Tabar M. Effect of satellite on Tehran young religious beliefs and values. 2007.1995; [4 screens]. Available atURL; http://libportal.imamreza. ac.ir/documents/10157.pdf.2007.PP: 1-26.

32- Patel V, Flisher AJ, Hetrik S, Mc Gorry P. Mental health of young people: a global public-health challenge.

Lancet2007; 369(9569): 1302-13. 